\title{
Powders for powder bed fusion: a review
}

\author{
Silvia Vock ${ }^{1} \cdot$ Burghardt Klöden ${ }^{1} \cdot$ Alexander Kirchner $^{1} \cdot$ Thomas Weißgärber $^{1} \cdot$ Bernd Kieback $^{1,2}$
}

Received: 18 November 2017 / Accepted: 29 January 2019 / Published online: 9 February 2019

(c) The Author(s) 2019

\begin{abstract}
The quality of powder used in powder bed-based additive manufacturing plays a key role concerning process performance and end part properties. Even though this is a generally accepted fact, there is still a lack of a comprehensive understanding of the powder property-part property relationship. However, numerous investigations focusing on selected powder properties and their corresponding influence on process aspects or final part properties have been published in recent years. Still, generalized statements on powder requirements for a defined process performance are not available. This can be attributed to the fact that the community has not yet come to an agreement which characterization techniques are most suitable for powder characterization in the additive manufacturing context and in most cases only selected aspects have been investigated for special powder materials. The aim of this review is to assess these building blocks of knowledge and to provide an overview on the current state of the art.
\end{abstract}

Keywords Powder for additive manufacturing $\cdot$ Powder characterization methods $\cdot$ Powder flowability $\cdot$ Laser beam melting $\cdot$ Electron beam melting $\cdot$ Powder bed fusion $\cdot$ Powder bed-based additive manufacturing

\section{Introduction}

The need in industry for fast, reproducible, and close-toprocess powder characterization techniques is steeply rising with the increasing application of powder bed fusion (PBF) technologies. It is a generally accepted fact that the quality of powders used in PBF is key for the process performance and final part quality [1-8]. Hence, the comprehensive understanding of powder influence in the PBF process is a basic requirement to pave the way for regular fabrication of components on an industrial scale with precisely predefined and reproducible properties. Furthermore, the thorough understanding of required powder properties for a given part quality will help to reduce powder costs by facilitating the choice of powder other than the ones offered by providers of PBF machines. According to Wohlers et al. powder costs are the second or third largest cost associated with producing

Burghardt Klöden

burghardt.kloeden@ifam-dd.fraunhofer.de

1 Fraunhofer Institute for Manufacturing Technology and Advanced Materials IFAM, Branch Lab Dresden, Winterbergstr. 28, 01277 Dresden, Germany

2 Institute of Materials Science, Technische Universität Dresden, 01062 Dresden, Germany additively manufactured (AM) parts and, therefore, the cost of producing metal powder will be important to the growth of the metal AM market [9]. A regular employment of the $\mathrm{PBF}$ techniques in the industrial environment is only imaginable if the challenging task of understanding powder influence on the process performance will be satisfactorily solved $[10,11]$.

There is an increasing awareness of the importance of a reliable powder metrology, which is evidenced by the activities of international and national standardization organizations. The main effort is being carried out at the international level by ASTM and ISO [11, 12]. Also national activities on standardization can be registered like the Association Francaise de Normalisation (AFNOR) in France, who approved a standard on powder specifications (XPE 67-010:2012) [11], which has been replaced in 2014 by NF E67-01. In 2014 the ASTM F3049 was approved, which is the first powder specific standard developed by ASTM F42 [2]. This is a standard, which refers to already existing standards (e.g. ASTM F3049-14) that may be applicable for the characterization of virgin and used-metal powders processed in additive manufacturing systems. However, Monzón et al. conclude in their overview on standardization activities that requirements for a broader application of AM cannot be solved by the existing general standards for materials used in other processes [11]. 
Researchers at National Institute of Standards and Technology (NIST) formulated measurement science needs for PBF in an extensive report, which also includes a section on preprocess measurements [7]. Furthermore, there are ambitions to develop standard test methods for raw metal powder characterization at NIST.

The present review aims to give an overview on past and current research activities focusing on the influence of powder quality on different aspects of the process and part properties. To this end, literature not only in the field of additive manufacturing is reviewed, but also research on powder behavior from other fields is included. As a matter of course, this review does not claim to be comprehensive by any means. However, the aim is to serve as a starting point to build up a data base comprising the possible influencing parameters and their impact on the PBF process and final part properties.

\section{Overview on powder bed AM processes}

ISO/ATSM 52900 defines seven process categories in chapter 3.2. Of these, two contain powder bed-based processes, namely Binder Jetting (BJT) and powder bed fusion (PBF). Whereas for BJT the process category is equivalent to the technology, PBF is subdivided into laser beam melting (LBM), electron beam melting (EBM) and selective laser sintering (SLS). Table 1 lists these technologies and typical properties. One more distinct difference between BJT and PBF is that the first is a two-step technology involving the manufacturing of a green body by AM and subsequent debindering and sintering, whereas the latter directly melts and sinters the material, respectively. For this paper only PBF will be considered.

\section{Quantification of research activities}

The assessment of the complex interaction between powder properties and additively manufactured part quality requires a categorization and prioritizing of the various powder parameters. Each distinct powder property can influence multiple features of the build process and with this it affects different aspects of the final part quality. Therefore, it is instructive to first summarize the various relevant physical and chemical powder properties and to evaluate, which processing step is influenced in what manner by each of it. Therefore, the scheme shown below (Fig. 1) has been developed, enabling to record the findings of the research activities to date.

The powder properties can be subdivided into multiple levels. The lowest level describes the pure physical or chemical property of the individual particles (named in the scheme in Fig. 1: powder properties). The second level describes the behavior of the powder ensemble as a whole (named in the scheme: bulk powder behavior). The third level describes the behavior of the powder under process-specific conditions (named in the scheme: in-process performance). It seems to be likely that the bulk powder behavior reflects the combined effect of certain powder properties and in the same way the in-process performance reflects the combination of different aspects of bulk powder behavior. Finally, the sum of various aspects of each level influences distinct key features describing final part quality, such as density, surface quality etc. (see Fig. 1). It can be assumed that the closer the characterization method comes to the actual process conditions, the clearer the relationship to the final part property will be. However, since such testing techniques are not available by default up to now, the aim is to find relationships between the different levels of powder properties and correlate them to in-process performance. To test the powder properties on the single particle scale one can use standardized, simple, mostly cheap and fast methods. According to Wohlers et al. powder bed fusion system manufacturers are able to approximate, e.g, powder flowability by defining powder distribution, particle size, and flowability specifications [13, p. 58]. However, the authors also mention that these are only proxies for lack of better methods [13, p. 58]. To interconnect the properties of the individual powder particle with bulk powder behavior, in-process performance and finally part property is a challenging task, due to the fact, that some properties of powder particles can have contrary effects on the next level properties [14].

Table 1 Overview on powder bed AM technologies with typical process properties

\begin{tabular}{llllll}
\hline Process & Energy source & Materials & $\begin{array}{l}\text { Particle fraction } \\
(\mu \mathrm{m})\end{array}$ & Layer thickness & Pre-heating \\
\hline LBM & Laser & Metals & $10-60$ & $30-60$ & Yes (start plate, up to 500 $\left.{ }^{\circ} \mathrm{C}\right)$ \\
EBM & Electron beam & Metals & $50-150$ & $50-100$ & Yes (electron beam, $\left.700-1100{ }^{\circ} \mathrm{C}\right)$ \\
SLS & Laser & Polymers & $20-80$ & $100-150$ & Yes $\left(180-380^{\circ} \mathrm{C}\right)$ \\
BJT & Furnace heating & $\begin{array}{c}\text { Metals, polymers, } \\
\text { ceramics }\end{array}$ & $<25$ & $50-100$ & No \\
& & & &
\end{tabular}




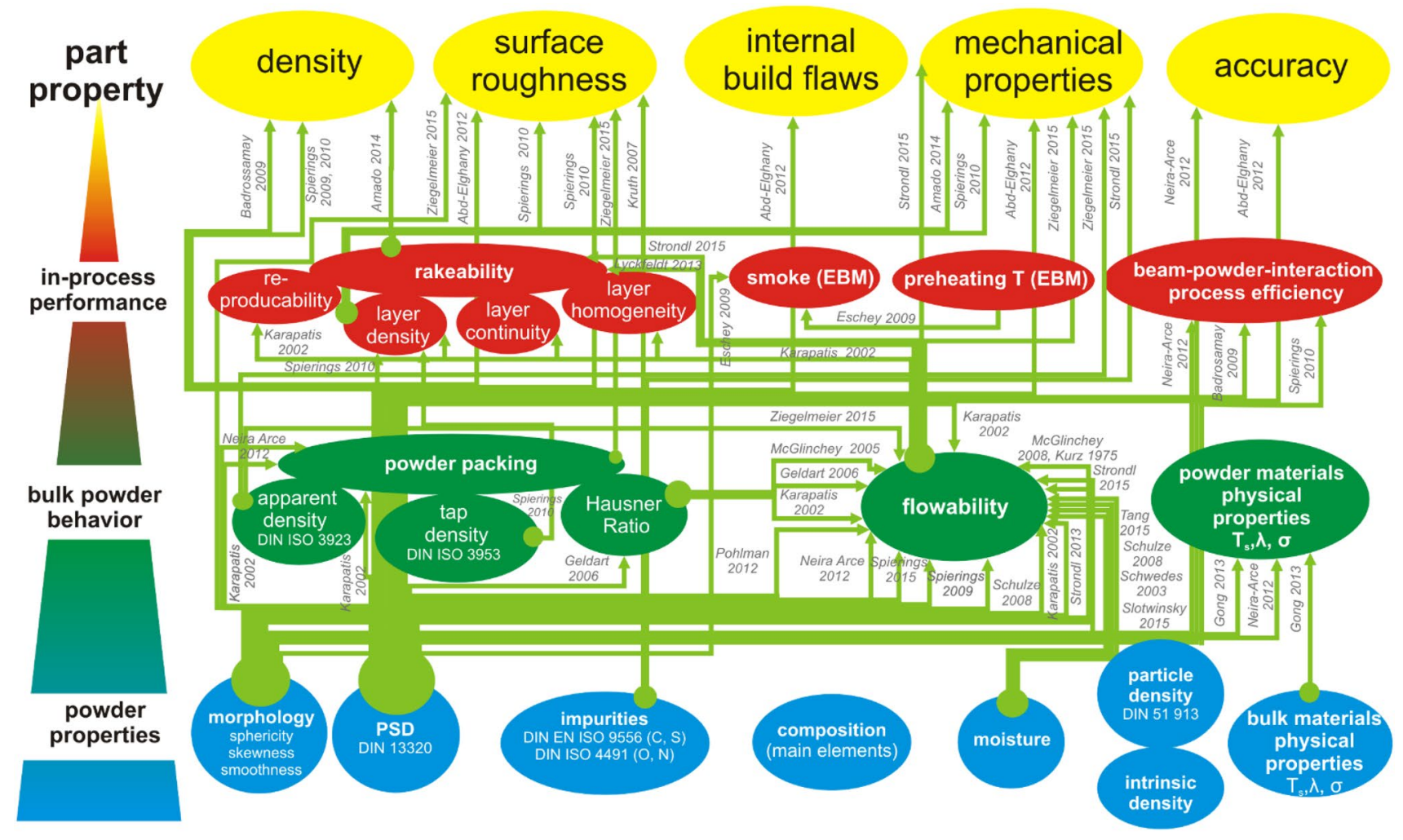

Fig. 1 Visualization of the relationships between powder properties, bulk powder behavior, powder performance in process and finally the manufactured part quality as elaborated by different research groups

To connect powder properties to bulk powder behavior, it is not important in which field of science the investigations were conducted. These dependencies are of general nature and not connected to the process in which the powders will be used. Basic knowledge on the behavior of bulk powders is available, e.g, in fields of powder metallurgy, pharmacy or construction technology. It is obvious that the actual composition of the powder particles will influence not only the end properties of the final part, but also moisture adsorption profiles and particle-particle interaction forces. However, the scheme (Fig. 1) illustrates that the influence of intrinsic material properties on bulk powder behavior has not yet been widely investigated.

Even though the reported dependencies are not always consistent and sometimes only considered in a very general way, the developed scheme (Fig. 1) can help to identify properties which are of major interest and reveals where the focus of research has been to date.

The occurrence of connections of the elements to lower, as well as higher level properties gives a quantitative impression about the focus of current research on the property interdependencies. While PSD's and particle morphology's influence on a multitude of other properties has been in the focus of numerous research activities (in agreement with the findings of the specification example given in the previous section), only punctual investigations exist on, e.g,. bulk materials physical properties and moisture. Concerning the influence of composition and powder particles density, no statements could be found, even though it is believed that these powder properties definitely have an influence on the in-process performance and final part quality. How flowability can be influenced by powder particle properties has been elaborated over many years in different fields of science and by a large amount of research activities. The influence of flowability itself on in-process performance and part property was the object of interest of several investigations in the past few years. In the group of in-process performance the rakeability is the most investigated property. Astonishingly, important aspects of in-process behavior such as the preheating temperature, which is relevant in Laser Powder Bed Fusion (LPBF) as well as in Electron Beam Melting (EBM) processes and the occurrence of smoke events (certain spread of powder particles) are not often related with powder properties and bulk powder behavior. In contrast to this, mechanical properties and the surface roughness of final parts are more often investigated in dependency of their powder properties and behavior.

In the following sections a more detailed view of the research activities on the relationships between the different components defined in Fig. 1 is given. 


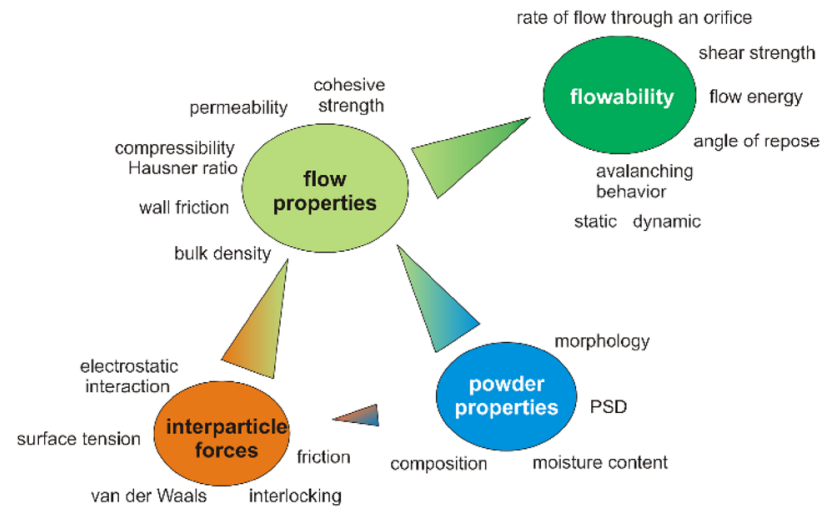

Fig. 2 Schematic visualization of the connection between the terms "flowability" and "flow properties" and respective parameters. The scheme is based on descriptions of Prescott et al. and expanded by the findings of this literature review [15]
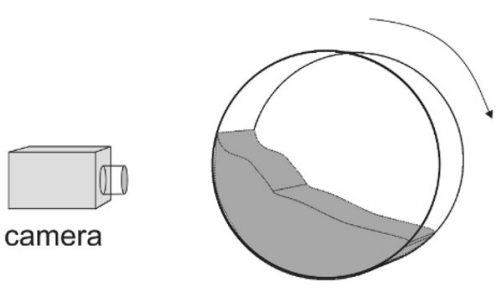

Fig. 3 Schematic drawing of the principle of a dynamic avalanche angle measurement using a Revolution Powder Analyser [16]

\subsection{Flowability: a key role}

In the previous section, powder flowability has been identified as a bulk powder property with a distinguished position. However, flowability is not one comprehensive property of bulk powder. Rather, flowability is an umbrella term describing the complex behaviour of powder, when it is mobilized or subjected to stress. The following scheme (Fig. 2) illustrates the multiple aspects of powder flow and the fact that flowability is not an inherent powder property [15]. Prescott et al. define the term "flow property" as specific bulk characteristics and properties of a powder that affect flow and can in principle be measured. Flow properties themselves are influenced by the powder properties and the interaction between the smallest powder units, the particles. While flow properties are independent of the equipment in which they were determined, the term "flowability" always has to be connected with equipment and the way in which it was tested.

To be able to test flowability relevant for the process under investigation, the testing device should come as close as possible to the process conditions [16-19] (Fig. 3). In PBF the forming a homogenous powder layer is the process step, where powder flowability plays a major role. Depending on the equipment used, different mechanisms exist for this powder spreading or dispensing step. The most common method is the use of a metallic blade, a roller or a rake for generating a powder layer with a precise layer height. A summary of commonly used methods can be found in the work of Foivos [20]. Another important aspect of flowability analysis is the capability of the characterization technique to differentiate between variations in powder quality, which might be small, but can have a major influence on the processability of the powder [19].

Numerous possibilities exist to test powder flowability. Among them, widely used and standardized methods, such as the Hall flowmeter funnel (ASTM B213) and the Carney funnel (ASTM B964) as summarized in ASTM F3049-14. To apply these simple and cheap methods for the qualification of AM powder is intuitive. However, Sun et al. conclude in their study on titanium powder that the flowability as tested by the Hall funnel does not allow a distinction between powders concerning their applicability in EBM [21]. Also Schulze mentions the following critical aspects of funnel flow tests in general: depending on the type of filling (operator influence), the flow through the orifice is depending on the aeration of the powder [18]. From this he concludes that funnel tests are only simple comparative tests not allowing a quantitative statement on powder flow. Nonetheless, a correlation between certain rheological properties, such as the cohesivity, of steel powders with varying PSD and morphology and Hall flow test results were found by Strondl et al. [22]. Spierings et al. also review different powder flow measurement techniques [4]. They consider the Hall flow test as closer to AM process than other techniques, but still come to the conclusion that this technique is not best suited. They argue that the technique is restricted only to superior flowing powders, while more cohesive powders, which are still good enough for AM, cannot be tested. They conclude from this that Hall flow is not best suited for AM powder characterization [4]. For LPBF powders, which have typically a smaller average particle size $(25-45 \mu \mathrm{m})$ and tend to be more cohesive than EBM powders $(40-105 \mu \mathrm{m})$, this might be valid. In the case of EBM powders the probability is lower that this limit is reached. Concluding, Hall tests might be suitable for ranking of different powder qualities used in AM, especially in EBM. Nonetheless, more research is required to ultimately decide if Hall flow is a technique which resolves changes in powder quality, leading to a different in-process performance.

Another straightforward and widespread method is the determination of the compressibility by means of the Hausner ratio (HR) as described in the standard ASTM D748109 . The HR is defined by the ratio of bulk and tap density. $\mathrm{HR}=1$ characterizes a bulk solid which is not compressible. This value is connected to the case of best flowability [18]. According to Schulze, the method can be used for 
comparative studies of fine grained powders but does not allow quantitative conclusions on flowability [18]. Spierings et al. conclude from own experience and the evaluation of a literature review, that the HR is not correlating well with other more sophisticated methods [4]. It is argued that "measuring the HR ratio is too far away from the situation in AM processing" and hence the method is not well suited for AM powder characterization. However, again there can also be found research results in literature supporting a contrary view.

Schmid et al. present a Round Robin Testing of the flowability of polymer SLS powders based on tap and bulk density. The parameters were analyzed manually with the aid of a plastic measuring cylinder. 9 SLS labs took part in the interlaboratory comparison. The obtained values demonstrate that the procedure is applicable to rank the quality of different SLS powders. An aged SLS powder could be clearly distinguished from virgin powder [17]. Also Karapatis can profit from the consideration of HR when comparing the behavior of different SLS powders (WC-Co, $\mathrm{Co}, \mathrm{Ti}, \mathrm{Ni}$ ) [14]. While tap and apparent density are not found to be connected to the behavior in the funnel test (Carney funnel), the HR values of the powders are well related to the flow rates. Karapatis concludes from his experiments that powders with HR below 1.2 flow well, while above they flood the funnel. Further, he concludes that powders with a high compaction ability can be deposited with a higher density. Geldart et al. find a near-perfect linear relationship between HR and the angle of repose [23]. From this it is concluded that both parameters are good indicators of powder flowability. McGlinchey assigns HR an indicator role as to how powders will likely behave, but it should not be relied only on this information [24, 25]. From the above review of partly contrary findin gs concerning the significance or applicability of the HR it remains difficult to deduce a concluding statement. Unless there will be more work on the relation between HR and in-process performance of a variety of different powders used in AM, the question of as to whether this parameter is of use has to remain unanswered.

The angle of repose (AOR) is again a widespread method to characterize bulk solids. It is especially applicable for free flowing to slightly cohesive homogenous powders [24]. It is supposed to be useful to rank materials concerning their flowability [25]. Schwedes similarly states that the method is applicable for free-flowing bulks but reproducibility worsens for cohesive bulks [26]. Schulze criticizes that the angle is depending on the chosen technique of cone formation and is, therefore, not a pure parameter of the measured bulk solid [18]. Geldart et al. developed an own equipment for the measurement of the angle of repose, which is commercially available [27]. It is found that the so measured AOR is closely correlated to HR. However, the authors claim that AOR is to be preferred as it is easier to measure and involves more powder movement such as often occurs in powder processing. Further, the authors conclude that the AOR can be used to characterize a wide range of powders to determine their flowability [23]. With respect to the AM process Sun et al. state that the static AOR is not useful for the decision whether a powder will be processable or not in a AM device. Due to the small amount of information concerning the usability of AOR in powder characterization for AM, it will be necessary to perform further investigations to find out whether there is a connection between AOR and in-process performance. Especially for the case of EBM powders, which fulfill the prerequisite of a free-flowing behavior it could be interesting to monitor this relationship. Anyhow, it will be necessary to differentiate between the various test methods allowing to determine AOR (nine methods according to Schwedes [26]).

A large group of testing methods is summarized under the topic of shear testers. A comprehensive summary is given by Schwedes and also by Schulze $[18,26]$. Spierings et al. conclude that the method is not applicable for AM powders due to the fact that the powders are tested under a compressive load. This disagrees with the statement that a more cohesive bulk solid will show worse flowability at higher as well as at lower compression in general [28]. The compression should not be regarded as an exclusion criteria in this case. It is used to obtain a predefined powder sample and a defined and known stress state. Furthermore, a special advantage of the ring shear tester is the possibility to measure at very low normal stress. This is especially important for free-flowing bulk solids $[26,29]$. The shear testers are able to rank powder used for AM, has been recently shown by Lyckfeldt et al. [30], who applied a shear head in a powder rheometer (FT4, Freeman Technology), applying a similar procedure as used by the Jenike shear cell [16]. The shear test parameters, such as ultimate yield strength, cohesion and flow function, all correlated very well with the observed quality of powder layer formation. A recent comparative study of different shear cells by Koynov et al. showed that the ranking of powders concerning their flowability was independent of the shear cell type, even though a certain variation in numerical values was observed [31]. However, they also conclude that their study underlines the statement that shear cells are less suitable for free-flowing materials. To be able to ultimately decide whether shear testing is an adequate method for characterizing powders for AM, a comprehensive study has to be performed.

In recent years, powder testing with a powder rheometer has become popular [1, 3, 16, 19, 30, 32-35]. Very promising results have again been reported by Lyckfeldt et al. and Strondl et al. testing steel powders used in AM [22, 30]. Measuring stability index, specific energy, and conditioned bulk density, all rheological parameters obtained with a Freeman FT4 rheometer, correlated well with the 
performance during powder layer formation [30]. Clayton et al. were able to distinguish between virgin and used metal powder and mixtures thereof [19]. Strondl et al. conclude from their study that powder rheology is a useful method to determine differences in flow properties of powders used in AM [3, 22]. Concluding, even though more studies are needed, powder rheology turns out to be a promising technique to characterize AM powder with respect to flowability.

Likewise, the characterization of powders concerning their dynamic avalanche angle, has gained increasing attention $[4,5,16,17,36-39]$. The principal idea was first published by Kaye et al., who investigated the use of avalanche studies to describe rheological properties of alumina powder [40-42]. The device measures the dynamic avalanching behavior of powder in a rotating disk and allows for a statistical evaluation of multiple avalanches. Soh et al. introduced the indices avalanche flow index and cohesive interaction index to describe avalanche flow properties in such a device (AeroFlow, TSI Inc., not available anymore) [37]. The results for pharmaceutical powders reveal that these indices are well suited to describe powder flow and powder cohesiveness. The characterization of polymer powders by Krantz et al. revealed that AOR and an averaged avalanche angle can be related linearly [16]. It is argued that this is due to the similar stress state to which these techniques subject the powder. The work of Spierings et al. focuses on the applicability of dynamic flow properties, as measured with a commercial dynamic powder flow analyser (Revolution Powder Analyser, RPA, available from different suppliers, e.g., Mercury Scientific Inc.), on the qualification of powders used in LPBF. The authors were able to quantitatively correlate optical powder evaluation based on operator experience with the measured flowability parameters. Therefore, the statistical distribution of the avalanche angle and surface fractal were included in the calculation, as well as the ellipticity (deviation from perfect spherical to ellipsoidal form) of the particles. The result shows a good correlation between the calculated and the observed flowability within the standard error. Pohlman et al. aimed to identify influencing factors on flowability of titanium powders produced by the Armstrong process [38]. The authors were especially interested in evaluating the effectivity of the attempt to improve the shape, and thus flowability, of the titanium particles. Therefore, they used a self-build rotating tumbler and recorded the angle of reposes as function of the Froude number, which is defined by the tumbler size and rotational speed. With this the authors were able to deduce similar flow behavior of processed and unprocessed powder. Amado et al. modified the commercially available RPA in a way that it is capable of measuring flow properties at elevated temperatures to emulate process conditions as present in the powder during the SLS process [38]. Schulze criticizes the dynamic avalanche measurement as this technique is based on a chaotic process and there is a lack of theory behind it (Schulze [18, p. 195]). However, the above-mentioned results reveal a promising correlation between measured parameters and AM processrelevant properties.

As it can be deduced from the literature review above, the term flowability must be specified with regard to the applied testing device. However, some basic rules can be formulated, which can be assumed to be valid for most of the testing strategies. The following relations between powder properties and flowability are of general nature:

- flowability increases with decreasing width of the PSD $[18,39,43,44]$.

- flowability generally improves with coarser particles [3, $14,18,39,45,46]$.

- Flowability decreases with increasing moisture content until saturation with liquid [18, 26, 44, 47-49].

\subsection{The impact of particle size distribution}

The influence of PSD on flowability was already discussed above, here the remaining PBF aspects are discussed as reported in literature. As visualized in the scheme (Fig. 1) the influence of the PSD on all kind of powder characteristics and also on final part property plays a major role in the investigations published to date.

Whereas flowability is a term depending on the context in which it is used, PSD is a property which is unambiguously defined by the dimensions of the single particles of the bulk solids and which is not depending on any other external parameters. However, considering the method used for the determination of the PSD, several issues and limitations can occur [50]. In the following, these limitations and uncertainties are neglected and it will be assumed that the findings given in literature are independent on the applied characterization method.

PSD has been found to influence layer densities in LPBF. Wide PSDs, biased towards fine particles, that is a multimodal PSD, lead to higher layer densities [14]. Karapatis et al. formulated several criteria for tailoring PSD with respect to its powder bulk density. Among them, the size ratio $d_{50} / d_{10} \geq 10$ and the criteria for a biasing towards fine particles $d_{90}-d_{50} / d_{50}-d_{10} \leq 1$. From theoretical and experimental considerations, Karapatis concludes that for good flow a narrow PSD is necessary (in accordance with the general conclusion given above) and for a high powder bulk density a wide distribution is required. And for the SLS process performance he states that a narrow PSD is beneficial to avoid segregation. This illustrates how contradictory the requirements for only one parameter can already be with respect to different aspects of a PBF process. 
Further, it has been shown by a multitude of authors that the PSD has an influence on final part quality (produced either by SLS, LPBF or EBM). Details on this can be found in the Sect. 3.6.

How the PSD influences bulk powder physical properties such as thermal conductivity was investigated by Gong et al. [51]. The authors find that the thermal conductivity of the bulk powder is approximately half of the solid material. They conclude from their findings that thermal conductivity is very sensitive to powder geometry characteristics, which drastically affects the thermal behaviour during electron scan melting. Neira Arce experimentally investigated the difference in thermal conductivity for two Ti6Al4V powder feedstock materials prepared by plasma rotating electrode process (PREP) and gas atomized process (GA), respectively, which are characterized by different PSDs [6]. The GA powders, which consist of smaller particles than the PREP powders show a higher thermal conductivity than the GA powders.

From the large amount of observed correlations between PSD and other process relevant aspects as well as final part quality reviewed above, it is clear that PSD is an important powder characteristic and has to be carefully tailored. However, it is not a parameter which can be used without additional information to decide how the powder will behave in the process.

\subsection{The impact of morphology}

To describe the impact of morphology on bulk powder characteristics and further on in-process performance and final part quality is complex and can not be answered by simple relationships. According to Schulze particle shape affects flow properties, but general statements are not possible [18]. In the case of coarse particles often smooth, spherical particles flow better than rough, sharp-edged, non-spherical particles. But in the case of fine particles, which are cohesive and between which adhesive forces play a major role, rough particles may exhibit a more favorable flow behavior [18]. Spierings et al. find the degree of ellipticity is effecting flowability (atomised nickel and iron powders). An increase in ellipticity improves flowability in general [4]. However, the investigations by Pohlman et al. on the role of particle shape influence on flow properties in the case of titanium powder produced by the Armstrong process revealed that PSD can be a more important factor than the particle shape [39]. Karapatis summarizes from a literature review that sphericity is favorable for good flow behavior, optimal packing density, and for performance in the SLS process for layer deposition (numerous metal powders, such as pre-alloyed $\mathrm{Ni}$ and $\mathrm{Co}$, commercially pure $\mathrm{Ti}$, WC-Co composite powder, $\mathrm{W}-\mathrm{Cu}, \mathrm{Ni}-\mathrm{Al}$ ) [14]. Strondl et al. found that recycled EBM powder particles show impact marks leading to lower flowability versus new powder (steel powders) [3]. With respect to ductility changes of the final part the morphology change is not rated to be of significance.

Even though, it is clear that there is an impact of morphology, it will be difficult to quantify it and to construct an unambiguous relationship to in-process performance and final part property. However, further studies are needed here to enlighten this complex relationship.

\subsection{Aspects of in-process performance}

\subsubsection{Test of raking behavior}

The rakeability is the most investigated in-process performance aspect related to PBF (compare Scheme 1). Despite this, the overall amount of investigations is small.

Karapatis studies influence factors on powder layer quality. He identifies powder flow and powder packing as the most contributing properties [14]. To quantify layer forming quality, Karapatis performs layer density measurement through weighing. It is found that the three investigated powders show higher layer densities than the corresponding apparent densities, which is attributed to the slight compaction during the deposition process. Further, it is revealed that in general layer density tends to increase with layer height. Spierings et al. claim more generally, that the tapped density of powders is not a sufficient parameter to distinguish powders with respect to their rakeability and the resulting layer density [36]. Sun et al. state that neither flowability, nor AOR allow a prediction as to whether a powder is suitable for AM or not [21]. Strondl et al. conclude from their experiments on new and recycled versions of Ti-6Al-4V powders, that certain variations in powder flow properties (measured with a powder rheometer, FT4, Freeman Tech.) are not critically affecting powder layering or the melting process. A more detailed look on the requirements for good powder layer formation in a $3 \mathrm{D}$ printing device was performed on stainless steel powders by Lyckfeldt et al. [22, 30]. It is concluded that the degree of cohesion has to be low with regard to good flow properties but in the same time the powder layer should stay uninfluenced by shear stresses when depositing the next powder layer, which implies a high enough flow energy driven by a high tap density rather than cohesive forces.

In-process performance has been correlated with part properties only by Spierings and Amado (both belonging to the same working group) $[17,38]$. As already mentioned above, Spierings et al. found that coarser powders lead to a lower powder layer density and an increased surface roughness of the final part. A lower powder layer density further leads to a reduced amount of beam energy reaching the underlying material, which causes an incomplete fusion and 
in the end a reduced mechanical strength in build direction [52]. Amado et al. only generally state that powder spreading quality influences the mechanical properties and homogeneity of the part density [38].

The influence of the powder layer morphology on the formation of the molten track has been studied theoretically using multi-physical modeling by Leitz et al. [53]. For the case of molybdenum it has been shown that the LPBF process is highly sensitive to the powder particle arrangement in the powder layer. It was found, for example, that variations in particle size and imperfections of the powder layer influence the width of the molten track.

Only two contributions were found, which experimentally address the powder layer formation. Sun et al. investigated the powder layer formation quantitatively under EBM process condition [21]. They developed a powder deposition system (universal powder bed-UPB) which is identical to the deposition system in an ARCAM A1 machine. This enabled the authors to rake the powder under conditions similar to the process conditions and to analyze the raking quality by a digital camera and a subsequent statistical image analysis. The method was shown to be a useful tool for analyzing the applicability of different powders prior to the actual process. For the case of laser sintering of polymer powders, van den Eynde et al. developed an own setup for powder raking [54]. It enables the qualitative assessment of powder layer smoothness and the quantitative determination of powder layer density. Three polymer powders were tested with this setup. The parameters showed a good correlation with the known processability of these powders in the laser sintering process. Both setups need further development and more statistical data of different powder types to be applicable in a standard manner for the prediction of powder applicability. Particularly, the parametrization and quantification of the powder layer quality have to be further developed. However, this approach seems very promising for future powder assessment.

It can be summarized that the existing reports on the raking behavior/powder layer formation are mainly of general nature. Only Karapatis, Sun et al. and van den Eynde et al. emulate process conditions during powder layer deposition. To systematically study the influence of powder and bulk properties on the raking behavior and further to correlate these findings with final part quality, more systematic studies with such powder layer forming devices will be necessary. Therefore, each powder deposition system has to be investigated separately. Still missing are suitable parameters which allow for a quantitative assessment of the resulting powder layer qualities.

\subsubsection{Powder properties at elevated $T$}

Additionally to the powder behaviour under a mechanical stress similar to the process conditions, the powder behaviour at an elevated temperature is of importance [38].

Amado et al. criticize that the effect of extrinsic powder properties is not so intensively investigated as intrinsic powder properties [38]. A prediction of necessary powder properties for a homogeneous layer spreading is seen as an important point to reduce development time and costs. To test the influence of elevated temperatures on the powder behaviour a Revolution Powder Analyser by Mercury Scientific Inc. has been equipped with a heated core cylin$\operatorname{der}\left(25-120^{\circ} \mathrm{C}\right.$-relevant for polymer powders) [38]. The authors analyzed the Avalanche Angle and Surface Fractal in Flowability mode as well as Total Volume Expansion Ratio in the Fluidization mode at different temperatures. It was found that the elevated temperature has a clear effect on the flowability of the tested polymer powder. This especially relates to the Surface Fractal, which indicates a change in flow behavior above the glass transition point. On the other hand, the Avalanche Angle is not sensitive to changes in temperature. Further, a maximum pre-heating temperature can be defined, where the particles start to clump together.

The effect of an elevated temperature is not only of importance with regard to the rakeability but also with regard to the necessary preheating temperature in both processes LPBF and EBM. In the case of a simulation model for LPBF the residual stress reduction is under focus [55], whereas in the case of EBM the preheating can have an influence on the probability that sudden scattering of powder, called smoke event, occurs. Preheating is reported to be necessary to prevent smoke by various authors [56-58]. Effects that lead to sudden powder spreading were also examined [57] with the authors reasoning that primarily the electrostatic charge of powder particles is responsible for that. Counteractive measures are proposed, of which pre-heating has the most pronounced effect. However, concerning pre-heating also the contradictory observation has been made that particle morphology and the diameter of the electron beam are of more importance regarding smoke events than preheating temperature by Eschey et al. [59]. The authors observed a charge and discharge phase of the powder particles, which are driven by electrostatic forces (both) and Lorenz force (only discharge). Increasing the defocus of the beam was beneficial in avoiding smoke as well as using non-spherical powders. Recently, it has been further reported that the preheating temperature has a significant impact on the thermal conductivity of the powder bed [60]. This has consequences on the amount of necessary support structures around the part to be build. 
In conclusion, the relevance of testing powder behavior and intrinsic powder properties at elevated temperatures to properly evaluate in-process performance has been shown in individual studies. For a more substantial understanding further principal investigations are necessary. The results of these studies will contribute to a more fundamental understanding of the correlation between powder properties and in-process behavior.

\subsubsection{Properties of recycled powders}

Up to this point various powder properties and their impact in PBF were discussed based on the starting material. Principally, only a small portion of the powder that is introduced in the machine is actually applied to build up the part. Most of the powder is left and can be reused in the subsequent build jobs. This fact makes PBF potentially a resource-efficient process. How far the efficiency extends strongly depends on the condition of the un-melted powder. Therefore, the effect of recycling on powder, process and part properties is in the focus of numerous research activities.

Powder recycling can be done in various ways. The following strategies are mentioned in literature (compare Table 2):

- A: used and sieved powder is mixed with virgin powder after each build in constant proportion (definition according to Lutter-Günther et al. [74]).

- B: used powder is mixed with powder of the same age after each cycle (cycle is defined here as the sum of build jobs after which the powder mass is reduced such that no further build is possible) [74].

- C: reintroducing sieved powder after each build job without mixing with other powders.

- D: used and sieved powder is added to the top of the unused virgin powder, no mixing takes place.

Further, it has to be distinguished between powders which were exposed to a continuously repeated similar build job and powders which were exposed to varying build jobs. The investigations discussed in the following have chosen the first approach throughout.

Lutter-Günther et al. determined the maximum number of possible use cycles for recycling strategy B regardless of powder quality degradation. This allows to judge the approximate number of meaningful reuse cycles which should be investigated to improve powder efficiency. The calculation was based on the input parameters powder loss, build volume utilization, powder batch size, and powder coating dosage factor. As a result, the build volume utilization was shown to have the strongest influence on the powder degression rate. The natural maximum number of use cycles varies around an average of 35, ranging from 1 to 117 cycles, with typical powder batch sizes of $100-1000 \mathrm{~kg}$. These values give the upper limit of powder cycles for the case that no powder quality degradation takes place in this range.

Table 1 summarizes several PBF recycling studies with respect to the observed effect on powder properties and part properties. Most of the published recycling studies stay well below the upper natural cycle limit as calculated by LutterGünther et al. (Table 2, column 2). Most likely due to the fact that strategy $\mathrm{C}$ is the mostly applied recycling approach (Table 2, column 3). The effect of recycling differs between EBM and LPBF. However, even inside the EBM and LPBF groups the effects on powder and parts differ. The reason for this might be the fact that the reuse times differ considerably. Also the recycling strategies might vary in certain details even though the $\mathrm{C}$ strategy is the mostly used one.

Summarizing the findings from the literature listed in Table 2 it can be concluded for all materials that even if an effect on powder properties is observed, the effect on final part quality is, in most cases, small.

\subsection{Final part quality}

Eventually, the driving force for investigating powder particle and bulk properties and their impact on process relevant aspects is the aim to reveal their correlation with the final part quality with respect to part density, surface quality, mechanical properties, part accuracy and internal build flaws. Ideally, it will be possible to predict part property variations depending on variations in powder properties for similar processing conditions. However, this will persist to be a complex task as optimal processing conditions might also vary with different powder properties [59].

To date, the majority of the investigations focus on the influence of PSD on final part quality. Spierings et al. find that the PSD should be biased in the direction of fine particles. This allows the finer particles to fill the voids between the coarser ones, which then leads to higher part densities and improved surface qualities [52], whereas bigger particles can be beneficial for higher breaking elongations [52]. Similar results are reported by a number of authors $[45,75$, 76]. In contrast to this, the influence of the width of the PSD is not such straightforward. Liu et al. connect a narrower PSD with a higher ultimate tensile strength and larger hardness for steel parts [77]. In the same time, they find that a wider PSD is connected with a higher powder bed density, higher density of the parts, and smoother surfaces of the surfaces parallel to the build direction [77]. Compared to this, Ziegelmeier et al. report the opposite (for thermoplastics). An increase of the proportion of large particles and a narrower PSD lead to a smoother surface of the sintered parts [46]. For the shore hardness and E-modulus the authors find no connection to the PSD [46]. Similarly, Lutter-Günther et al. found a counter-intuitive relationship between PSD, 
Table 2 Overview on studies concerning powder recycling (HCF—high cycle fatigue, UTS—ultimate yield strength)

\begin{tabular}{|c|c|c|c|c|c|c|}
\hline Powder type & Max reuse times & Recycling strategy & Process & $\begin{array}{l}\text { Effect on powder proper- } \\
\text { ties }\end{array}$ & Effect on part properties & References \\
\hline Ti-6A-4V & 69 & Unspecified & EBM & $\begin{array}{l}\text { Chemical comp.: oxygen } \\
\text { content increases } \\
\text { Morphology: less spheri- } \\
\text { cal, variety of defects }\end{array}$ & $\begin{array}{l}\text { Microstructure: constant } \\
\text { Elongation at break: } \\
\text { decrease } \\
\text { HCF: decrease }\end{array}$ & Popov et al. [61] \\
\hline Ti-6Al-4V & 12 & $\mathrm{C}$ & EBM & $\begin{array}{l}\text { Morphology: constant, } \\
\text { only occasional defor- } \\
\text { mations } \\
\text { PSD: constant }\end{array}$ & $\begin{array}{l}\text { Chemical comp.: Al con- } \\
\text { tent decrease, } \mathrm{C} \text { - and } \\
\text { O-content increase } \\
\text { Microstructure: constant }\end{array}$ & Petrovic et al. [62] \\
\hline Ti-6Al-4V & 21 & $\mathrm{C}$ & EBM & $\begin{array}{l}\text { Chemical comp.: } \\
\text { O-content increase, } \\
\text { Al-and V-content slight } \\
\text { decrease } \\
\text { Morphology: less spheri- } \\
\text { cal, distortion } \\
\text { PSD: narrower } \\
\text { Flowability (Hall): } \\
\text { improves }\end{array}$ & $\begin{array}{l}\text { UTS: increase } \\
\text { Yield strength: increase } \\
\text { Tensile elongation: } \\
\text { constant }\end{array}$ & Tang et al. [44] \\
\hline Ti-6A-4V & Unspecified & Unspecified & $\mathrm{EBM} / \mathrm{LPBF}$ & $\begin{array}{l}\text { Chem. comp: oxygen } \\
\text { increases } \\
\text { PSD } \\
\text { EBM powder (coarser): } \\
\text { gets finer } \\
\text { LPBF powder (finer): } \\
\text { gets coarser } \\
\text { Flowability (rheom.) } \\
\text { EBM powder } \rightarrow \\
\text { degrades } \\
\text { LPBF powder } \rightarrow \\
\text { improves } \\
\text { Packing } \\
\text { EBM powder: constant } \\
\text { LPBF powder: increase }\end{array}$ & $\begin{array}{l}\text { SLM } \\
\text { UTS: constant } \\
\text { Yield strength: constant } \\
\text { Ductility: decrease } \\
\text { Impact toughness: } \\
\text { decrease }\end{array}$ & Strondl et al. [3] \\
\hline Ti-6Al-4V & 12 & $\mathrm{C}$ & LPBF & $\begin{array}{l}\text { PSD: coarser and wider } \\
\text { Flowability: increase } \\
\text { Apparent density: } \\
\text { increase }\end{array}$ & $\begin{array}{l}\text { Density: increase } \\
\text { Surface roughness: } \\
\text { increase } \\
\text { Hardness: slight increase } \\
\text { UTS: increase }\end{array}$ & Seyda et al. [63] \\
\hline Ti-6Al-4V & 38 & $\mathrm{C}$ & LPBF & $\begin{array}{l}\text { Chem. comp.: oxygen } \\
\text { and nitrogen content } \\
\text { increases } \\
\text { PSD: slightly narrower, } \\
\text { slightly coarser } \\
\text { Flowability (Hall): } \\
\text { increase } \\
\text { Powder density: constant } \\
\text { Morphology: constant }\end{array}$ & UTS: slight increase & Grainger [64] \\
\hline Ti-6Al-4V & 5 & $\mathrm{C}$ & LPBF & $\begin{array}{l}\text { PSD: slightly coarser } \\
\text { Morphology: roughened } \\
\text { surface } \\
\text { Chemical comp.: constant } \\
\text { O and N content }\end{array}$ & $\begin{array}{l}\text { Chemical comp.: } \\
\text { increased O-content }\end{array}$ & O'Leary et al. [65] \\
\hline AlSi10Mg & 18 & $\mathrm{C}$ & LPBF & $\begin{array}{l}\text { PSD: slightly finer } \\
\text { Morphology: slightly } \\
\text { elongated } \\
\text { Chemical comp.: constant }\end{array}$ & No effects & Maamoun et al. [66] \\
\hline
\end{tabular}


Table 2 (continued)

\begin{tabular}{|c|c|c|c|c|c|c|}
\hline Powder type & Max reuse times & Recycling strategy & Process & $\begin{array}{l}\text { Effect on powder proper- } \\
\text { ties }\end{array}$ & Effect on part properties & References \\
\hline AlSi10Mg & 8 & $\mathrm{C}$ & LPBF & $\begin{array}{l}\text { Chemical comp.: constant } \\
\text { PSD: slightly finer } \\
\text { Tap and apparent density: } \\
\text { slight increase } \\
\text { Morphology: constant }\end{array}$ & $\begin{array}{l}\text { UTS: decrease } \\
\text { Yield strength: decrease } \\
\text { HCF: decrease } \\
\text { Surface roughness: } \\
\text { constant }\end{array}$ & Del Re et al. [67] \\
\hline AlSi10Mg & 4 & A & LPBF & $\begin{array}{l}\text { PSD: constant } \\
\text { Flowability (FT4): } \\
\text { constant }\end{array}$ & & Vock et al. [68] \\
\hline IN718 & 14 & $\mathrm{C}$ & LPBF & $\begin{array}{l}\text { Morphology: constant } \\
\text { PSD: constant, except } \\
\text { agglomorates } \\
\text { Chemical comp.: constant }\end{array}$ & $\begin{array}{l}\text { Microstructer: constant } \\
\text { Porosity: constant } \\
\text { Mechanical properties: } \\
\text { constant }\end{array}$ & Ardila et al. [69] \\
\hline IN 718 & 2 & Unspecified & LPBF & $\begin{array}{l}\text { PSD: significant increase } \\
\text { in fines } \\
\text { Morphology: recycled } \\
\text { powder more ellip- } \\
\text { soidal, more oblique } \\
\text { particles }\end{array}$ & $\begin{array}{l}\text { Porosity/pore diameter/ } \\
\text { pore spacing: weak } \\
\text { correlation between two } \\
\text { powder conditions }\end{array}$ & Kappes et al. [70] \\
\hline $316 \mathrm{~L}$ & & A & LPBF/EBM & $\begin{array}{l}\text { Surface chemistry: } \\
\text { growing of Cr-Mn-rich } \\
\text { oxide particulates }\end{array}$ & & Leicht [71] \\
\hline Steel 1.4404 & 5 & $\mathrm{C}$ & LPBF & & UTS: constant & Geisert et al. [72] \\
\hline Stainless steel & 11 & $\mathrm{D}$ & LPBF & $\begin{array}{l}\text { PSD: constant, slight } \\
\text { shift to fines } \\
\text { Flowability (Hall): } \\
\text { increase } \\
\text { Apparent density: } \\
\text { increased } \\
\text { Chemical comp.: con- } \\
\text { stant, increase of C } \\
\text { Microstructure: bcc phase } \\
\text { increased } \\
\text { Morphology: constant }\end{array}$ & $\begin{array}{l}\text { Surface roughness: } \\
\text { constant } \\
\text { Density: constant } \\
\text { Hardness: constant } \\
\text { Mechanical properties: } \\
\text { constant }\end{array}$ & Jacob et al. [73] \\
\hline
\end{tabular}

powder bed density and final part density [78]. A wide PSD, which leads to a higher powder bed density, resulted only in a middle-rate part density.

Investigations on the influence of other powder properties on the final part quality are rare, although it is obvious that there must be an interconnection between morphology, impurities, moisture content, particle density, and bulk material properties and the final part properties. In fact, for Ti-6Al-4V Strondl et al. investigated the difference between new and recycled powder [3]. Tensile and yield strength are identical for both powder types, while the ductility and the impact toughness tend to go down for recycled powder. The authors connect this to the change in oxygen content.

Beside the powder properties the bulk powder behavior has an influence on the final part. However, only the work by Ziegelmeier et al. and Liu et al. was found to establish this relationship in detail. Ziegelmeier et al. report for thermoplastics that increased tensile properties can be achieved with powders with higher bulk densities. An increased bulk density also leads to an increase in part density and a decline of voids inside the sintered components [46]. With this goes an enhancement of ultimate tensile strength and elongation at break with increasing bulk density [46]. On the other hand, a decline in packing density of bulk powder results in an increase of bulk powder surface roughness (as measured in a RPA) and with this it increases the surface roughness of the fabricated part. Liu et al. measured powder bed densities by selectively melting a container and weighing the powder inside of it. With this method they found that a lower powder bed density results in lower part densities [77].

It can be assumed that flowability holds a central significance also for the mechanical part properties, even though information that can be found in literature is scarce. Again Ziegelmeier et al. found that an increasing flowability results in a positive trend for ultimate tensile strength, elongation at break, and reduction of porosity and pore volume [46].

The following table (Table 3) summarizes the above review on influencing factors on part quality. Significantly more investigations are needed to draw general conclusions from this. However, it can already be seen that contradictions 
Table 3 Powder properties and their influence on different aspects of part quality based on the literature cited in this chapter

\begin{tabular}{|c|c|c|c|c|c|}
\hline & Part density & Surface quality & Mechanical properties & Accuracy & Internal build flaws \\
\hline \multicolumn{6}{|l|}{ PSD } \\
\hline Narrow & & & $+[77]$ & & \\
\hline Wide & $+[77]+[14]$ & $+[77]$ & & & \\
\hline Coarse & & $-[76]-[78]$ & $-[76] 0[3,46]+[36]$ & $-[76]$ & $-[76]$ \\
\hline Fine & $+[52]+[45]+[75]$ & & $-[72]$ & & $-[72]-[70]$ \\
\hline \multicolumn{6}{|c|}{ Bulk density } \\
\hline Low & $-[77]$ & $-[46]$ & & & $0[78]$ \\
\hline High & $+[46]+[79]$ & & $+[46]$ & & $+[46]$ \\
\hline \multicolumn{6}{|c|}{ Flowability } \\
\hline \multicolumn{6}{|l|}{ Low } \\
\hline High & & & $+[46]$ & & $+[46]$ \\
\hline
\end{tabular}

“+” denotes a positive effect, “-" a negative effect, "0" for no effect. Each sign stands for the results reported in one citation can occur both, for one interconnection between part and powder property, as well as between powder property and different part quality aspects. While in the first case the reason of the contradiction has a methodological reason, the second case is a sign for the need of optimization to tailor the final part quality to fit the requirements.

\section{Identification of white spots}

Even though there have been extensive studies on connecting powder properties with bulk powder behavior in different fields of powder technology, the link to the specific PBF processes is still weak (compare Fig. 1). Especially the connection between bulk powder behavior and in-process performance is not well established, as well as the connection between in-process performance and final part quality. The main effort has been done to reveal the effect of powder properties, such as PSD and morphology on the final part quality. This is by the opinion of the authors a jump too large, skipping the intermediate steps which cover bulk powder behavior and in-process performance. For a better understanding of the relationships labeled in Fig. 1 more fundamental research is necessary. Furthermore, much more experimental data are necessary for reliable statistics, which will then allow to establish connections between powder properties and final part quality. To the authors opinion the most promising approach for a comprehensive picture is the establishment of large data bases containing all aspects, powder, process and part properties for different material classes. Sophisticated statistical methods can then be used to cluster the various powders with regard to their specific properties, to derive relationships between the physical entities and finally to enable a prediction of powder performance and part quality based on powder properties. First attempts toward this direction have been made by Baturynska et al. and Prater and Kappes et al. [70, 80, 81].

The description of powder behavior under process conditions is to date, naturally, not a well-established field. Here arises a need to develop new characterization methods and to define meaningful parameters, which further have to be connected to the final part. This holds for each of the elements labeled in Fig. 1 under the topic of in-process performance: the rakeability of the powder, the determination of optimal preheating conditions, the ability to predict smoke events, as well as the estimation of beam-powder-interaction efficiency. It further stands out that thermo-rheological investigations are, with exception of the work of Amado et al. [38], completely missing. EBM is a hot process and also LPBF is performed at elevated temperatures, thus modified powder behavior can be expected.

It is an accepted fact that process simulations are of great importance for the support of the material development procedures in PBF [82-84]. For simulating the melting step in the EBM and LPBF process, often predefined particle arrangements are used and the influence of different starting conditions, such as particle size distribution and powder bed homogeneity on the part properties is investigated [85, 86]. However, simulation of in-process performance, such as the raking or rolling step as a function of particle distribution, size, and morphology is still a challenging task and only limited work exists on this topic [84, 87]. To decrease computational effort, powder beds are often treated as continuum, averaging the effect of morphology, particle sizes and their distribution. To realistically calculate how particle properties and the interaction between particles will translate into the layer formation, especially at elevated temperatures, and further how they will translate into part properties after the melting step, require a large computational effort. Up to now, these sophisticated procedures are not available to a broad part of the AM community and are far from being 
a standard tool to apply for material development. In spite of this, the findings of simulations enlarge the basic process understandings, especially of those physical mechanisms, which cannot be observed during experiment, such as melt pool dynamics and material consolidation mechanisms [84].

An alternative to process simulation, is the experimental approach to quickly assess and understand in-process behaviour of powder. Standardized schemes have to be developed enabling a broad user-group applying them for their own material development procedures. Such scheme would for example comprise, as suggested by Evans et al., thermal cycles within the powder to allow for heat transfer and sintering process estimations. As a next step they suggest in-process testing of single and multiple layer builds using only a small fraction of powder. This is achieved by a so-called small volume insert. The last step includes the test of long-term reliability of the powder. Evans et al. are of the opinion that this approach will make materials development much easier and less costly [84]. The publication dates from 2005. However, more than 10 years later there is still a lack of experimental approaches to implement these or similar schemes.

\section{Conclusions}

All the reviewed reports on powder property, bulk powder behaviour, in-process performance and their crosscorrelations, as well as their influence on final part quality, eventually all have the aim to widen the range of applicable materials. This requires the pre-process determination of the applicability of a chosen powder in the AM process, the estimation of its in-process behaviour and the expected final part quality and in a next step, the pre-process localization of process parameter windows. This is of use for different actors in the PBF business. The powder manufacturer will be able to design his powder optimally for the PBF process and get access to a broader market. The PBF users will profit from a faster introduction of new material and the PBF device manufacturer will profit from the wider applicability of his device.

A multitude of different powders was used in the investigations on powder-part quality correlation summarized in this review. Additionally, different powder bed systems were applied (LPBF, EBM). Hence, quantitative conclusions are difficult to derive. But for all that, an evaluation on a qualitative level and a basic course of action for the development of a comprehensive powder qualifying procedure can be derived from the summarized results.

The review of the actual work leads to the conclusion that comprehensive powder qualification would not be possible solely by already standardized methods (apparent, tapped density, PSD, flowmeter). In most cases, a direct correlation between powder property and in-process behaviour is missing or the measured bulk powder property is not sufficient to differentiate between substantially different in-process behaviour of different powders. The bulk powder properties turn out to be useful to define basic requirements rather than differentiating between variations in process quality. For a more precise identification of crucial powder and bulk properties, the solution will be either a combination of various characterization methods for given process parameters or a more complex powder characterization technique exclusively designed for the specific PBF process.

OpenAccess This article is distributed under the terms of the Creative Commons Attribution 4.0 International License (http://creativeco mmons.org/licenses/by/4.0/), which permits unrestricted use, distribution, and reproduction in any medium, provided you give appropriate credit to the original author(s) and the source, provide a link to the Creative Commons license, and indicate if changes were made.

\section{References}

1. Clayton J, Millington-Smith D, Armstrong B (2015) The application of powder rheology in additive manufacturing. JOM 67:544-548

2. Slotwinski JA, Garboczi EJ (2015) Metrology needs for metal additive manufacturing powders. J Miner Met Mater Soc 67:538-543

3. Strondl A, Lyckfeldt O, Brodin H, Ackelid U (2015) Characterization and control of powder properties for additive manufacturing. JOM 67:549-554

4. Spierings AB, Voegtlin M, Bauer T, Wegener K (2015) Powder flowability characterisation methodology for powder-bed-based metal additive manufacturing. Prog Addit Manuf 2015:1-12

5. Amado A, Schmid M, Levy G, Wegener K (2011) Advances in SLS powder characterization. In: Proceedings of solid freeform fabrication 2011, pp 438-452

6. Neira Arce A (2012) Thermal modeling and simulation of electron beam melting for rapid prototyping on Ti6Al4V alloys. Dissertation, North Carolina State University, Raleigh

7. Mani M, Lane BM, Donmez MA, Feng SC, Moylan SP, Fesperman RR Jr (2015) Measurement science needs for real-time control of additive manufacturing powder bed fusion processes. Int J Prod Res. https://doi.org/10.6028/NIST.IR.8036

8. Slotwinski J, Moylan S (2014) Applicability of existing materials testing standards for additive manufacturing materials: NISTIR 8005. National Institute of Standards and Technology, Gaithersburg

9. Wohlers TT (ed) (2017) Wohlers report 2017: 3D printing and additive manufacturing state of the industry. Annual worldwide progress report, Fort Collins

10. Bourell DL, Leu MC, Rosen DW (2009) Roadmap for additive manufacturing: identifying the future of freeform processing 2009. https://wohlersassociates.com/roadmap2009A.pdf

11. Monzón MD, Ortega Z, Martínez A, Ortega F (2015) Standardization in additive manufacturing: activities carried out by international organizations and projects. Int J Adv Manuf Technol 76:1111-1121

12. Slotwinski J, Moylan S (2014) Metals-based additive manufacturing: metrology needs and standardization efforts. In: 2014 ASPE spring topical meeting, Berkeley 
13. Wohlers TT, Caffrey T (2015) Wohlers report 2015: 3D printing and additive manufacturing state of the industry annual worldwide progress report. Wohlers Associates, Fort Collins

14. Karapatis $P$ (2002) A sub-process approach of selective laser sintering. Doctoral thesis, EPFL, Lausanne

15. Prescott JK, Barnum RA (2000) On powder flowability. Pharm Technol 24:60-85

16. Krantz M, Zhang H, Zhu J (2009) Characterization of powder flow: static and dynamic testing. Powder Technol 194:239-245

17. Schmid M, Amado F, Levy G, Wegener K (2013) Flowability of powders for selective laser sintering (SLS) investigated by round Robin test. In: High value manufacturing: advanced research in virtual and rapid prototyping, pp 95-99

18. Schulze D (2008) Powders and bulk solids: behavior, characterization, storage and flow. Springer, Berlin, Heidelberg. https://doi. org/10.1007/978-3-540-73768-1

19. Clayton J Characterizing powders to optimise additive manufacturing. http://www.tctmagazine.com/3D-printing-news/characteri sing-powders-to-optimise-additive-manufacturing/

20. Foivos PG (2016) Development of a powder management mechanism for an SLS/SLM machine. National Technical University of Athens, Athens

21. Sun YY, Gulizia S, Oh CH, Doblin C, Yang YF, Qian M (2015) Manipulation and characterization of a novel titanium powder precursor for additive manufacturing applications. JOM 67:564-572

22. Strondl A, Lyckfeldt O, Angré A, Chasoglou D (2013) Characterisation of steel powders - correlation between particle characteristics and bulk properties. In: European powder metallurgy congress proceedings, pp 213-218

23. Geldart D, Abdullah EC, Hassanpour A, Nwoke LC, Wouters I (2006) Characterization of powder flowability using measurement of angle of repose. China Particuol 4:104-107

24. McGlinchey D (2008) Bulk solids handling: equipment selection and operation. Blackwell, Oxford

25. McGlinchey D (2005) Characterisation of bulk solids. Blackwell/ CRC Press, Oxford

26. Schwedes J (2003) Review on testers for measuring flow properties of bulk solids. Granul Matter 5:1-43

27. Geldart D, Abdullah EC, Verlinden A (2009) Characterisation of dry powders. Powder Technol 190:70-74

28. Schulze D (2016) Applicability of the Schulze ring shear tester for the characterization of powder for additive manufacturing. Personal communication

29. Schweiger A, Zimmermann I (1999) A new approach for the measurement of the tensile strength of powders. Powder Technol 101:7-15

30. Lyckfeldt $\mathrm{O}$ (2013) Powder rheology of steel powders for additive manufacturing. In: European powder metallurgy congress proceedings, pp 225-230

31. Koynov S, Glasser B, Muzzio F (2015) Comparison of three rotational shear cell testers: powder flowability and bulk density. Powder Technol 283:103-112

32. Freeman R (2007) Measuring the flow properties of consolidated, conditioned and aerated powders - a comparative study using a powder rheometer and a rotational shear cell. Powder Technol 174:25-33

33. Yan Z, Wilkinson SK, Stitt EH, Marigo M (2016) Investigating mixing and segregation using discrete element modelling (DEM) in the Freeman FT4 rheometer. Int J Pharm 513:38-48

34. Hare C, Zafar U, Ghadiri M, Freeman T, Clayton J, Murtagh MJ (2015) Analysis of the dynamics of the FT4 powder rheometer. Powder Technol 285:123-127

35. Clayton J (2017) Freeman technology: optimising metal powder characterisation with dynamic powder testing. Powder Metall Rev 6:69-71
36. Spierings AB, Herres N, Levy G (2011) Influence of the particle size distribution on surface quality and mechanical properties in AM steel parts. Rapid Prototyp J 17:195-202

37. Soh JLP, Liew CV, Heng PW (2006) New indices to characterize powder flow based on their avalanching behavior. Pharm Dev Technol 11:93-102

38. Amado A, Schmid M, Wegener K (2014) Flowability of SLS powders at elevated temperature. Report. https://doi.org/10.3929/ethza-010057815

39. Pohlman NA, Roberts JA, Gonser MJ (2012) Characterization of titanium powder: microscopic views and macroscopic flow. Powder Technol 228:141-148

40. Kaye BH, Gratton-Liimatainen J, Faddis N (1995) Studying the avalanching behaviour of a powder in a rotating disc. Particle Particle Syst Charact 12:232-236

41. Kaye BH (1997) Characterizing the flowability of a powder using the concepts of fractal geometry and chaos theory. Particle Particle Syst Charact 14:53-66

42. Kaye BH (1998) Characterization of powders and aerosols. Wiley, Weinheim

43. Kurz HP, Münz G (1975) The influence of particle size distribution on the flow properties of limestone powders. Powder Technol 11:37-40

44. Tang HP, Qian M, Liu N, Zhang XZ, Yang GY, Wang J (2015) Effect of Powder reuse times on additive manufacturing of Ti-6Al-4V by selective electron beam melting. JOM 67:555-563

45. Spierings AB, Levy G (2009) Comparison of density of stainless steel $316 \mathrm{~L}$ parts produced with selective laser melting using different powder grades. In: Proceedings of the annual international solid freeform fabrication symposium, Austin, pp 342-353

46. Ziegelmeier S, Christou P, Wöllecke F, Tuck C, Goodridge R, Hague R, Krampe E, Wintermantel E (2015) An experimental study into the effects of bulk and flow behaviour of laser sintering polymer powders on resulting part properties. J Mater Process Technol 215:239-250

47. Lu SL, Tang HP, Ning YP, Liu N, StJohn DH, Qian M (2015) Microstructure and mechanical properties of long Ti-6Al-4V rods additively manufactured by selective electron beam melting out of a deep powder bed and the effect of subsequent hot isostatic pressing. Metall Mater Trans A 46:3824-3834

48. Weiwei $\mathrm{H}$, Wenpeng J, Haiyan L, Huiping $\mathrm{T}$, Xinting $\mathrm{K}, \mathrm{Yu}$ $\mathrm{H}$ (2011) Research on preheating of titanium alloy powder in electron beam melting technology. Rare Metal Mater Eng 40:2072-2075

49. Slotwinski JA, Garboczi EJ, Stutzman PE, Ferraris CF, Watson SS, Peltz MA (2014) Characterization of metal powders used for additive manufacturing. J Res Natl Inst Stand Technol 19

50. German RM (2005) Powder metallurgy and particulate materials processing. Metal Powder Industries Federation, Princeton

51. Gong X, Cheng B, Price S, Chou K (2013) Powder-bed electronbeam-melting additive manufacturing: powder characterization, process simulation and metrology. ASME Early Career Technical Conference (ECTC), Birmingham, AL, USA, District F, Section 2, pp 59-66

52. Spierings AB, Herres N, Levy G (2010) Influence of the particle size distribution on surface quality and mechanical properties in additive manufactured stainless steel parts. Rapid Prototyp J 17:195-202

53. Leitz K-H, Grohs C, Singer P, Tabernig B, Plankensteiner A, Kestler H, Sigl LS Fundamental analysis of the influence of powder characteristics in selective laser melting of molybdenum based on a multi-physical simulation model. In: Proceedings of the 19th Plansee seminar 
54. van den Eynde M, Verbelen L, van Puyvelde P (2015) Assessing polymer powder flow for the application of laser sintering. Powder Technol 286:151-155

55. Branner G (2010) Modellierung transienter Effekte in der Struktursimulation von Schichtbauverfahren. Technischen Universität München, München

56. Zäh MF, Lutzmann S (2010) Modelling and simulation of electron beam melting. Prod Eng Res Dev 4:15-23

57. Sigl M, Lutzmann S, Zaeh MF (2006) Transient physical effects in electron beam sintering. In: Solid freeform fabrication symposium proceedings, Austin, pp 397-405

58. Kahnert M, Lutzmann S, Zaeh MF (2007) Layer formations in electron beam sintering. In: Solid freeform fabrication proceedings, pp 88-99

59. Eschey C, Lutzmann S, Zaeh MF (2009) Examination of the powder spreading effect in electron beam melting (EBM). In: Solid freeform fabrication symposium proceedings, pp 3-5

60. Smith CJ, Tammas-Williams S, Hernandez-Nava E, Todd I (2017) Tailoring the thermal conductivity of the powder bed in electron beam melting (EBM) additive manufacturing. Sci Rep 7:10514

61. Popov VV, Katz-Demyanetz A, Garkun A, Bamberger M (2018) The effect of powder recycling on the mechanical properties and microstructure of electron beam melted Ti-6Al-4V specimens. Addit Manuf. https://doi.org/10.1016/j.addma.2018.06.003

62. Petrovic V, Niñerola R (2015) Powder recyclability in electron beam melting for aeronautical use. Aircr Eng Aerosp Technol $87: 147-155$

63. Seyda V, Kaufmann N, Emmelmann C (2012) Investigation of aging processes of Ti-6Al-4 V powder material in laser melting. Phys Proc 39:425-431

64. Grainger L (2018) Understanding the effects of metal powder reuse in laser powder-bed fusion AM. In: Proceedings of Fraunhofer direct digital manufacturing conference

65. O'Leary R, Setchi R, Prickett PW (2015) An investigation into the recycling of Ti-6Al-4V powder used within SLM to improve sustainability. In: SDM'2015: 2nd international conference on sustainable design and manufacturing, Seville, Spain, 12-14 April 2015. http://orca.cf.ac.uk/81260/

66. Maamoun AH, Elbestawi M, Dosbaeva GK, Veldhuis SC (2018) Thermal post-processing of AlSi10Mg parts produced by selective laser melting using recycled powder. Addit Manuf 21:234-247

67. Del Re F, Contaldi V, Astarita A, Palumbo B, Squillace A, Corrado P, Di Petta P (2018) Statistical approach for assessing the effect of powder reuse on the final quality of AlSi10Mg parts produced by laser powder bed fusion additive manufacturing. Int J Adv Manuf Technol 231:1890

68. Vock S, Härtel M, Maiwald-Immer T, Wendt F, Burghardt K et al (2018) Powder assessment for powder bed based additive manufacturing. In: Proceedings of Fraunhofer direct digital manufacturing conference

69. Ardila LC, Garciandia F, González-Díaz JB, Álvarez P, Echeverria A, Petite MM, Deffley R, Ochoa J (2014) Effect of IN718 recycled powder reuse on properties of parts manufactured by means of selective laser melting. Phys Proc 56:99-107

70. Kappes B, Moorthy S, Drake D, Geerlings H, Stebner A (2018) Machine learning to optimize additive manufacturing parameters for laser powder bed fusion of Inconel 718. In: Ott E, Liu X, Andersson J, Bi Z, Bockenstedt K, Dempster I, Groh J, Heck K, Jablonski P, Kaplan M, Nagahama D, Sudbrack C, Chantal K, Sudbrack BA, Lerch TM, Smith IE, Locci DL, Ellis, Aaron C, Thompson BR (eds)Proceedings of the 9th international symposium on superalloy $718 \&$ derivatives: energy, aerospace, and industrial applications. The minerals, metals \& materials series. Springer, Cham, pp 595-610

71. Leicht A (2018) Aspects of building geometry and powder characteristics in powder bed fusion. Thesis, Chalmers University of Technology, Gothenburg
72. Geisert S, Fischer J, Klosch-Trageser M, Stolpe M (2018) Powder production processes - optimizing parameters for the generation of fine metal powders for additive manufacturing. In: Proceedings of Fraunhofer direct digital manufacturing conference

73. Jacob G, Brown CU, Donmez MA, Watson SS, Slotwinski J (2017) Effects of powder recycling on stainless steel powder and built material properties in metal powder bed fusion processes. National Institute of Standards and Technology, Gaithersburg

74. Lutter-Günther M, Gebbe C, Kamps T, Seidel C, Reinhart G (2018) Powder recycling in laser beam melting: strategies, consumption modeling and influence on resource efficiency. Prod Eng Res Dev 12:377-389

75. Schaumburg (2009) Improving productivity rate in SLM of commercial steel powders. Rapid, Illinois, pp 12-14

76. Abd-Elghany K, Bourell DL (2012) Property evaluation of 304L stainless steel fabricated by selective laser melting. Rapid Prototyp J 18:420-428

77. Liu B, Wildman R, Tuck C, Ashcroft I, Hague R (2011) Investigation the effect of particle size distribution on processing parameters optimisation in selective laser melting process. In: International solid freeform fabrication symposium: an additive manufacturing conference, pp 227-238

78. Lutter-Günther M, Horn M, Seidel C, Reinhart G (2017) Einfluss der Korngrößenverteilung auf Fließfähigkeit und Bauteilqualität beim Laserstrahlschmelzen. Influence of particle size distribution on powder flowability and part properties in laser beam melting. In: Kynast M, Eichmann M, Witt G (eds) Proceedings of the 14th rapid technical conference. Carl Hanser, München, pp 297-311

79. Li R, Shi Y, Wang Z, Wang L, Liu J, Jiang W (2010) Densification behavior of gas and water atomized $316 \mathrm{~L}$ stainless steel powder during selective laser melting. Appl Surf Sci 256:4350-4356

80. Baturynskaa I, Semeniuta O, Martinsen K (2017) Optimization of process parameters for powder bed fusion additive manufacturing by combination of machine learning and finite element method: a conceptual framework. In: 11th CIRP conference on intelligent computation in manufacturing engineering-CIRP ICME 17

81. Prater T (2017) Database development for additive manufacturing. Prog Addit Manuf 2:11-18

82. Markl M, Körner C (2016) Multiscale modeling of powder bedbased additive manufacturing. Annu Rev Mater Res 46:93-123

83. Gong X, Anderson T, Chou K (2014) Review on powder-based electron beam additive manufacturing technology. Manuf Rev 1

84. Evans S, Bourell R, L D, Beaman J, Campbell J (2005) SLS materials development method for rapid manufacturing. In: Solid freeform fabrication symposium proceedings, pp 184-196

85. Markl M, Bauereiß A, Rai A, Körner C (2016) Numerical investigations of selective electron beam melting on the powder scale. In: Fraunhofer-Gesellschaft 2016-proceedings of Fraunhofer direct digital manufacturing conference

86. Gürtler F-J, Karg M, Dobler M, Kohl S, Tzivilsky I, Schmidt M (2014) Influence of powder distribution on process stability in laser beam melting: analysis of melt pool dynamics by numerical simulations. In: Proceedings of the SFF symposium

87. Lee YS, Zhang W (2015) Mesoscopic simulation of heat transfer and fluid flow in laser powder bed additive manufacturing. In: Proceedings of the annual international solid freeform fabrication symposium

Publisher's Note Springer Nature remains neutral with regard to jurisdictional claims in published maps and institutional affiliations. 